\title{
Discursive Psychology as a method of analysis for the study of couple and family
}

\section{therapy}

\begin{abstract}
The field of couple and family therapy has benefitted from evidence generated from qualitative approaches. Evidence developed from approaches relying on language and social interaction using naturally occurring recordings of real-world practice have the benefit of facilitating practice-based recommendations and informing practice. The aim of this article is to provide an overview of one approach to discourse analysis, Discursive Psychology (DP), demonstrating how a social constructionist framework and focus on discourse can provide an important contribution to the field of therapy. To illustrate the methodological decisionmaking process for researchers and/or practitioners who utilise DP, we draw upon a videorecorded therapeutic session involving Tom Andersen. To conclude, we make recommendations for practitioners using DP to explore and examine therapeutic practice.
\end{abstract}

Key words: Family therapy, Tom Andersen, Discursive psychology, Accountability, Quality, Discourse Action Model. 


\section{Discursive Psychology as a method of analysis for the study of couple and family}

\section{therapy}

\section{INTRODUCTION}

In this article, we present discursive psychology (henceforth DP), a qualitative approach that examines what people accomplish through social interaction (Edwards and Potter, 1992). DP is one of many approaches to discourse analysis (see Jørgensen and Phillips, 2002), which is a relatively well-established approach and gaining popularity in the field of couple and family therapy. More particularly, in this article, we introduce DP and offer practical guidance for therapists who might choose to undertake research using this approach. Accordingly, we offer a practical overview of DP, which includes advice on the methodological decision-making processes, such as developing research questions, collecting data, and engaging in analysis. We consider the broader therapeutic context by critically assessing the role of evidence, quality indicators, and the possible benefits to the field.

Broadly, the field of couple and family therapy recognises the importance of utilising best evidence and learning new ideas or practices, while emphasising the importance of inspiring new ways to understand and address clients’ concerns (Ness and Strong, 2013). Tangible evidence collected from therapists' practice is a valuable way of contributing to the resource of practice-based evidence (O’Reilly and Kiyimba, 2015). Specifically, involvement in practice-based research allows practitioners to be more actively involved in research that is designed to have an impact on their work (Fox, 2003). It allows question development, research engagement and findings to be a reflexive and iterative process that feeds back into practice (O’Reilly and Kiyimba, 2015). Evidence comes in many different forms, using both quantitative and qualitative approaches. Therapists practicing qualitative research generally take an approach which explores how clients and therapists perceive and view a 'problem'. We argue that such research is important to this field and that an important form of evidence 
can be found via using the qualitative DP approach. This is because DP examines the interactions between therapists and their clients, investigating what they actually talk about and how this interaction is accomplished in the real world of therapy.

We suggest that evidence yielded from the study of social interaction is tangible, empirical and justifiable in that it is beneficial to inform the practice of therapy (Strong et al., 2008). Evidence generated from discursive studies has important benefits for those working in practice, as these studies present useful and translatable messages for therapists in terms of how they might use language in practice and how their clients interact with them (Kiyimba and O’Reilly, 2016). While the randomised controlled trial is still considered by many to be the best type of evidence to inform practice, qualitative evidence also plays an important role (Lester and O’Reilly, 2015). When engaging with evidence generated through a DP study, therapists can be guided towards looking beyond the conversation to see evidence of change, as well as how their dialogical actions are shaped by the ways in which clients respond to them during the interaction (Strong et al., 2008).

Necessarily, it is important that clinical fields undertake research that moves beyond determining what works best in therapy to explore how it achieves its goals; in this way, such research has direct relevance and impact for professionals engaged in the task of therapy (Rhodes, 2011). In the context of family therapy, the language produced becomes a focus for transforming everyday descriptions by re-contextualising them into therapeutically relevant understandings of the systemic difficulty (Roy-Chowdhury, 2006). This is important, as family therapists have long challenged the perspective that dysfunction is individual; rather, the 'pathology' reflects a wider system (McNamee and Gergen, 1992). Similarly, in couple therapy, neither individual is identified as the pathologized individual, but conceptually the difficulties are understood to be a function of the interaction between both parties. Whereas in family therapy there is usually one member who has been referred as the identified patient, 
this is not usually the case in couple therapy. Thus, the institutional context is slightly different. Nonetheless, there is potential within family therapy for sessions to be organised in which just the couple are present.

\section{Overview of discursive psychology}

Using approaches that focus on language make "intuitive sense”, as therapy in and of itself is fundamentally a form of conversation (McLeod, 2001, p.91). Thus, scholars have perhaps unsurprisingly argued that it is essential to include discursive research in the field of systemic therapy, as specifically this is useful for making sense of and assessing therapeutic interaction (Strong et al., 2008). Indeed, these approaches generally focus on language use, which is a central concern within the practice of therapy (Burck, 2005; Roy-Chowdhury, 2003). Such research allows for therapists and others to better understand how communication practices might be adapted or enhanced to maximise their impact on practice (Priebe and McCabe, 2008).

Discourse analysis approaches encompass a broad range of methodologies that focus on language and social interaction (Wetherell, 2001). These approaches share the assumption that language is performative, in that people do things with and through language. However, each of these approaches has specific views on the meaning(s) of discourse, and differing analytic foci. For example, some of these approaches to the study of discourse take a broad social, cultural and institutional position, examining the macro aspects of language; whereas other approaches take a more fine-grained, micro orientation to the study of language in use (Avdi and Georgaca, 2007).

As noted previously, our focus in this article is DP, which we suggest is a particularly useful discourse analytic approach for the study of family therapy. Generally, DP is attributed to the Loughborough school of thought, and, as an approach to the study of language, it was 
developed by scholars in response to a general dissatisfaction with traditional, cognitivist ways of making sense of psychological process (Edwards and Potter, 1992). Broadly speaking, three strands of DP have evolved, which were outlined by Potter (2012). The first strand originated in the early discourse analytic work that focused on identifying ‘interpretative repertories’. These were considered the main building blocks of this particular strand of DP and were argued to be concepts and categories in talk; that is, the common-sense concepts that people draw upon in everyday interaction. Modern use of this kind of DP tends to take a critical perspective (see Reynolds, 2013) and uses a range of data sources, including interviews and focus groups. The second strand of DP saw a shift towards the study of psychological matters and a more explicit theoretical framework of social constructionism (Potter and Hepburn, 2008), which functioned to re-specify psychological constructs, such as cognition and mental states, in more interactional ways. More particularly, discursive psychologists assume that psychological constructs are socially managed in and through every day talk and text. This form of DP became a distinctive approach with the work of Edwards and Potter (1992) who proposed the Discursive Action Model (DAM) as a heuristic framework to aid analysis and it is this form of DP that is the primary focus of this article. The third strand of DP built upon the second strand of DP, but was heavily influenced by conversation analysis (CA), which focuses specifically on the sequential order of talk. Potter (2012) reported that it was the engagement of DP with CA that led to discursive psychologists utilising a CA theoretical framework to inform decisions, such as the nature of data collection, and paying closer attention to the sequentiality of interaction. Conversation analysis (Sacks, 1992) is a qualitative methodology, which arose within the field of sociology, and attends to the sequential and structural nature of language in use.

While there are three strands of DP, they generally share common assumptions. First, DP has a primary focus on how people use language to accomplish social actions. This 
perspective influences how analysts engage with therapy data, for instance, they tend to examine the performative nature of the language being used by both a therapist and client. Examples of such include: how clients may blame each other for problems, how clients excuse their behaviour, and how clients might present a complaint to a therapist. Second, DP prefers the use of naturally occurring data (although critical DP does not necessitate this). Naturally occurring data is generally defined as data which does not depend upon the researcher's involvement or agenda (Potter, 2002). Third, the process of undertaking a DP analysis is slightly different to some other qualitative approaches, as DP focuses on the nature of the talk, which includes an emphasis on the prosodic (pitch, volume, and so on), paralinguistic (non-verbal gestures), and the sequential nature of turn-taking (conversational structure). This approach to analysis relies less on a coding framework, which is fairly common in qualitative approaches, and more on 'unmotivated looking', which is an analytic perspective used in conversation analysis (Hutchby and Woffitt, 2008).

\section{Discursive psychology: theory and practice}

An important feature of DP is its social constructionist theoretical framework, particularly in terms of how the approach understands psychological constructs and processes. In psychology, the traditional perspective has sought to position mental health as being a property of an individual, with a focus on 'curing' that individual. However, social constructionism seeks to reframe understandings of psychological constructs, such as personality, memory or psychopathology, positioning mental states as being constructed through social interaction (Burr, 2003; O’Reilly and Lester, in press, a). Further, it challenges the assumptions of traditional cognitive psychology (Lester, 2011), and argues that what people say is always rhetorically formulated and situated (Edwards, 2012). Therefore, DP requires analysts to examine discourse in its own right, and not see language as a vehicle to 
access any underlying mental processes (Edwards and Potter, 1992). In this way, DP is an approach, rather than simply a method, as it is also a way of thinking about psychological concepts (Potter, 2012).

The social constructionist foundations of DP and the critical questioning of traditional cognitivist concepts is one that is often shared by therapists. Indeed, "couple and family therapists have been at the forefront of social constructionist innovations to therapeutic practice for well over a generation” (Ness and Strong, 2014, p. 81). Social constructionists view language as quintessential, and communication and social interaction are of analytic interest (Ness and Strong, 2013). For this reason, many therapists take a social constructionist stance in their work as they seek to understand the clients’ diverse understandings and descriptions of experience (Strong and Ness, 2014). Therapists pay close attention to communication practices, and many accept that it is impossible to access the reality of the speaker, and instead explore how clients respond as the conversation unfolds (Strong et al., 2008).

Understandably, then, DP is a particularly valuable tool for critically evaluating and exploring institutional practices, as it focuses on micro turn-by-turn analysis of interactions. Such a focus makes DP especially well-suited for the study of family therapy (Tseliou, 2013). In particular, DP offers the opportunity to scrutinise therapist's interventions to extract important information to be considered in clinical reflection (Diorinou and Tseliou, 2014). Reflection is widely practiced by therapists and used to consider the efficacy of various techniques or approaches; therefore, such a practice lends itself to research processes that prioritise the kind of in depth analysis common to discourse analysis approaches, such as DP (Strong et al., 2008). For example, DP has been used in researching the discourse of the therapist (for a review see Tseliou, 2013), including how questions are utilised by therapists in practice (Diorinou and Tseliou, 2014). DP has also been used to explore the ways in which 
families construct their versions of events to therapists as a way of managing blame (O’Reilly and Lester, in press, b; O’Reilly and Parker, 2014) and how they exonerate responsibility and accountability (Patrika and Tseliou, 2016). This is also the case for discursive couple's therapy research, whereby analysis has highlighted the use of extreme case formulations for managing accountability regarding the accuracy of descriptions (Edwards, 2000). Other discursive psychology research with couples has demonstrated how discursive work can create attributions of identity formulations and counter accusations of malingering (HortonSalway, 2001). An appreciation of how family members use rhetorical resources to present versions of events can be useful in considering how therapists may maintain a neutral position to manage therapeutic alignment (Stancombe and White, 2005).

\section{Discursive psychology research questions}

Couple and family therapists undertaking social constructionist research will be able to reflect upon the nature of issues they face in their practice. However, for research to be conducted effectively it needs to be guided by a clear research question. Developing a research question in DP is not always straightforward, and in a recent review of discourse studies and family therapy, many were found to have inadequately defined research questions (Tseliou, 2013). The concern for DP in developing research questions is its commitment to valuing a datadriven, non-researcher-directed investigation using inductive inquiry. Its social constructionist underpinning means that there is a broader interest in understanding how social actions are accomplished in interaction, and thus the common research process of designing a specific research question at the outset of a project is not always considered entirely appropriate (Potter, 2012).

Notably, DP has no specific focus of inquiry and in that sense the research questions iteratively emerge throughout the process of analysis. Thus, any question that guides the 
collection of data must be open and broad, not restricting that inquiry. In this way, discursive psychologists aim to understand what happens within certain kinds of interactions. By keeping the inquiry broad and open in this way, it allows the data to reveal novel and insightful interests that were not predetermined from the beginning. For this article, therefore we had no preconceived ideas about the nature of the problem or the data. Our research question at the beginning was simply; 'what happens in family therapy?' However, through the iterative process of doing discursive analysis, the question became more focused, as the authors engaged with the existing literature and the data simultaneously. Through this critical engagement, the question was narrowed to investigate the ways in which interactions between therapists and clients produce particular interactional outcomes and which discursive processes contributed to those outcomes. More detailed attention to the data led to a more specific focus on 'how blame and responsibility were managed by the different parties'. This informed the final process of collecting specific data extracts that related to the refined research question.

\section{Family therapy data for discursive psychology}

To address the research question, it is important to attend closely to the data. As we have already alluded, DP tends to favour the use of naturally occurring data to answer its questions and to understand the institutional task in hand. This is because it is appropriate to examine the actual talk that takes place in therapy sessions (Roy-Chowdhury, 2006). Specifically, naturally occurring data in the form of video-recordings of actual practice can facilitate therapist learning (Ness and Strong, 2013). By analysing naturally occurring clinical encounters there is the potential to place researchers and therapists on an equal footing which can encourage productive partnerships and recognise that neither has a privileged understanding as both can provide important insights (Chenail and Morris, 1995). 
In utilising naturally occurring data it is important to avoid decontextualising the data (Sacks, 1987). However, we recognise that there is some tension regarding exactly what constitutes naturally occurring data; yet, it is generally agreed to be data that would still exist as a natural event if it were not captured by the researchers. In other words, the researcher's actions are key to determining the status of the data, as a natural event would still take place without the researcher being able to record it or collate the texts for analysis (Potter, 2002). For the family therapist, then, the family would still attend therapy, the therapist would still practice, even if the video was not recording this interaction for research. This preference reflects the position that discursive psychologists take in exposing the limitations of the cognitive perspective in psychology (Potter, 2002).

It is this rejection of cognitivism that has resulted in many discursive psychologists to privilege the collection of naturally occurring events, such as recording therapy sessions as they unfold in their 'natural' environment. This preference stands in contrast to researcher generated data, such as interviews or focus groups, which have been argued to be legitimate ways of accessing participants 'real' cognitions, or expressing their 'true' mental states (Potter and Hepburn, 2005). In other words, discursive psychologists argue against the idea that you can access what someone 'really thinks' through a method like an interview or survey. The problem with these methods is that the respondent is treated as neutral, reporting on events and treating cognitions as if they are tangible and accessible (Potter and Hepburn, 2005). Alternatively, discursive psychologists argue that ascriptions, descriptions, and positions are rhetorically organised and interactionally accomplished through social interaction.

\section{Assuring quality in the approach}


Through analysis DP provides a useful mechanism for the interrogation of family therapy data. It is however important to adhere to the quality indicators inherent to the perspective. There are rigorous criteria for ensuring the quality of a DP study and unfortunately critics of the approach have sometimes confused the focus on natural interaction with an "interpretative free-for-all” (Edwards, 2012, p.431). This is not the case, as DP is guided by six key indicators for quality that generally reflect broader discourse analytic approaches (Antaki et al., 2003). These indicators have been explained most clearly by demonstrating some of the ways in which discursive research can be done 'badly', so as to highlight the potential pitfalls and difficulties faced in doing this kind of analysis.

The first potential pitfall identified by Antaki et al. (2003) was 'under-analysis through summary’ which was deemed insufficient. In other words, it is not uncommon for researchers to merely summarise the themes and fail to analyse the discourse. Second was 'under-analysis through taking sides’ as it was argued that analysts should not take a position of alignment or dis-alignment with the speakers as this flattens the complexity of the analysis. Third was ‘under-analysis through over-quotation or isolated quotation' and referred to when researchers simply allow the quotations to speak for themselves rather than providing analysis. Fourth was ‘the circular discovery of (a) discourses and (b) mental constructs’. In other words, the ostensible discovery of an aspect of the interaction should not be presupposed and interactions should not be thought of as reflections of inner thoughts or feelings. Fifth was ‘under-analysis through false survey’ and refers to when analysts inappropriately treat the findings as if they reflect all members of a particular category. Finally, was 'under-analysis through spotting' which represented cases of when researchers are overly reliant on simply spotting certain discursive devices at the expense of examining how conversational resources function to accomplish social actions. The framework thus 
presents a way of recognising poor quality DP and demonstrates ways of doing DP to avoid these pitfalls.

Alongside avoiding poor quality DP, there are also important considerations for promoting high quality analysis. First, it is important to assure the quality of the recording as in both couple and family therapy there are multiple speakers and potential for overlapping talk. Second, the transcription needs to be as detailed as possible to accurately represent not just what is said, but also how it is said. The more detailed the transcript, the better able the audience is to assess the quality of the analysis presented to them. Third, analytic claims are grounded in the data, which provides a robust way of checking analytic interpretations (Pilnick et al., 2010). Fourth, it is considered useful to identify and report deviant cases as attention to deviant cases ensures that claims made from the data are not made prematurely (Potter, 2012). Fifth, it is important to validate the findings by considering the scope of the analysis (Potter and Wetherell, 1987). In other words, coherence of discourse claims within a specific study are mapped against claims from previous studies, as discursive psychologists locate their work in relation to previously published work. Finally, quality assessment includes the reader's evaluation (Potter, 2012). DP research aims to demonstrate its main arguments by illustrating the steps involved in analysis of specific extracts of data. Thus, the transparent process of analysis shows the reader how it was conducted and how a specific point was reached (Wood and Kroger, 2000).

\section{METHOD}

\section{Context}

To demonstrate the benefits and value of a DP approach to study couple and family therapy, we draw upon a segment of video-recorded data from the work of family therapist, Tom Andersen. In so doing, we highlight how DP might be useful for a close interrogation of 
recorded family therapy interactions. Andersen (1987) argued that therapists have a complex task and can encounter instances of a 'stuck system' due to an insular way of thinking; thus, he proposed the need for a reflecting team. Such an approach in therapy requires the observation of interactions between the family and the therapist (Lange, 2010) from which comments made by the reflecting team to both clients and therapist, mean that a new understanding of the problem can be established (Andersen, 1992). This preference for scrutinising the interactions between therapists and families is already a firmly embedded practice for family therapists. In addition to the 'live' reflecting in practice that occurs during the session, recording and transcribing sessions to analyse using DP also affords the opportunity for reflecting on practice (see Schőn, 1987).

Using a DP approach, we examined pre-provided data that consisted of a naturally occurring family therapy session. The session was a live consultation from the California Family Study Centre. The session includes a couple, Lisa and Michael attending, with the therapist Jennifer providing the intervention, and no children present. Tom Andersen, who took up the position of a reflecting team member facilitating the overall process, oversaw the session. During this segment of therapy, although Andersen made only minimal verbal contributions, the couple provided information about their marriage and family, and the inherent conflicts that occurred between them. This was video-recorded data and thus the paralinguistic features were also available to the analysts. For discursive psychologists, there is a preference to undertake one's own transcription rather than paying a professional transcriptionist as transcription is seen to part of the analytic process. However, for practical reasons a professional may be asked to produce a basic verbatim version first as was the case for the data used in this study. As DP relies on the Jefferson method of transcription (Jefferson, 2004), the verbatim transcripts were then revisited to add in paralinguistic features 
in such a way as to reflect how the words were spoken to facilitate analysis (see Appendix A for a table with the meaning of the Jeffersonian transcription conventions used).

\section{The Discursive Action Model}

To frame the analysis, those practicing DP often utilise the Discursive Action Model (DAM), or at least draw upon its principles. It is necessary to recognise that this is not a model in the usual sense, as it is not founded in cognitive concepts, rather it is argued to be a conceptual scheme that captures the key features of speaker's discursive practices (Edwards and Potter, 1992). Notably, not all authors make explicit reference to the model in their contemporary DP work, but may still utilise the general principles, and not all three strands of DP (as outlined in the history) draw upon those principles. Nonetheless, the DAM was central to the original version of DP, and its core characteristics can still be seen in many modern DP studies. In the interests of pedagogy and appreciating the fundamental basis of DP, it is this model we utilise in this paper.

The DAM has three core aspects which are attended to during analysis which are, 'action', 'fact and interest', and 'accountability' (Edwards and Potter, 1992). The first aspect of the DAM reflects the central concern of DP, that people 'do things' with their talk, meaning that interaction is action-oriented and social actions are accomplished. In that sense, therefore, psychological concepts such as memories and attributions are considered as social actions not as mental states. The second aspect is fact and interest which is conceptualised broadly as the ways in which speakers present their descriptions as factual by way of handling possible misunderstanding of them having an interest in how the 'facts' are interpreted by others. This should not be thought of as a motivation of the speaker, but instead discursive analysts explore how interlocutors treat each other as being invested in their claims with desires and biases in relation to the way phenomena are reported (Edwards 
and Potter, 1992). Family therapists often work in a setting where 'stake and interest' are likely to be displayed by speakers; for example, as parents or children present their versions of events in a factual and disinterested way which is rhetorically designed to manage how motivations might be perceived. The final aspect of the DAM is accountability. Speakers routinely manage responsibility, blame and agency when reporting events (Edwards and Potter, 1992) and in so doing they present accounts for their actions. Notably, both the initial action and the reporting of that action in the current conversation constitute two levels of accountability (Potter, Edwards and Wetherell, 1993). Family therapy is a setting whereby blame and accountability are frequently invoked and managed by various parties. For example, it is relatively common for parents to seek to mitigate any potentially perceived forthcoming blame for their child’s difficulties (O’Reilly and Lester, in press, b).

\section{The process of analysis}

Engaging in DP requires taking an inductive approach and consistently re-engaging with the data. While historically there has been some resistance by those writing about DP to provide a series of procedural steps for doing this kind of analysis it is being increasingly noted that some explication is necessary to help those new to the approach. This does not equate to a 'stepwise procedure' typically found in other qualitative methods, but is presented more as a heuristic of the core stages. Potter (2012) argued that there are seven core iterative processes to doing analysis, and we outline these briefly here.

The first stage is the process of obtaining access to the naturally occurring data and securing participant consent. The nature of recording events that occur naturally, such as family therapy interactions may be challenging because of the need for trust. Second, sampling needs to be thought through carefully. While there is no specific regulation about sample sizes, it is necessary to build a sufficient interactional data corpus so that phenomena 
of interest can be examined. For DP, sample size does not relate to the number of participants as in other qualitative methods, but the volume of data, or the number of minutes of naturally occurring data recorded. The third stage is data management, which involves the collation of digital files or text-based documents, transcripts and analytic notes for a clear audit trail. Fourth, is transcription, which as we have noted is an essential aspect of the analytic process. This involves an iterative process of developing ideas and evolving the project. Fifth, new and more relevant research questions are developed and these can be finalised through the process of the analysis. Sixth, is the most crucial and time consuming stage of the process, which involves the analyst systematically examining the entire data set to build a corpus of examples of an interesting phenomenon. These examples are then carefully analysed using the principles of the DAM. The final stage is for the researcher to evaluate the quality of their study.

It is often advised for researchers to engage in data sessions with other analysts to interrogate the detail of the data and have open discussions of the discursive practices evident within it. This process of collaboration allows for different perspectives to emerge and for new ideas to be generated. This is also a useful confirmatory process by transparently working together with other researchers on the same data in relation to verifying the field validity of claims about social actions. Additionally, such group data sessions are useful training platforms for novice analysts to learn from more experienced researchers. The focus for such collaborative endeavours tends to be on identifying the main social actions being performed by the speakers and what may be at stake for the participants. The group can also focus on how psychological attributes are used as social resources within that interactional setting.

\section{FINDINGS}


Explicating the analytic process means attending to the core features of the DAM. While this is usually achieved in an integrated way, for illustration we have separated out the core features of the model to demonstrate the value and relevance of each of its components. In attending to the three core features of the model, we highlight how the clients and therapists orient to the institutional goals and proffer certain versions of reality.

\section{The DAM in practice}

The first element of DAM focuses on the action-oriented nature of language; that is, talk is assumed to be performative of social life. For example, it is through language in use that people go about casting blame, making a request, offering a compliment, etc. In other words, social life is accomplished in and through talk. Thus, a discursive psychologist seeks to make sense of what social action is being performed through speakers' language use. Extract 1 provides a useful example from the data in which Lisa is doing a very particular social action - one which is perhaps reasonably expected given the institutional context.

\section{Extract 1}

Lisa:

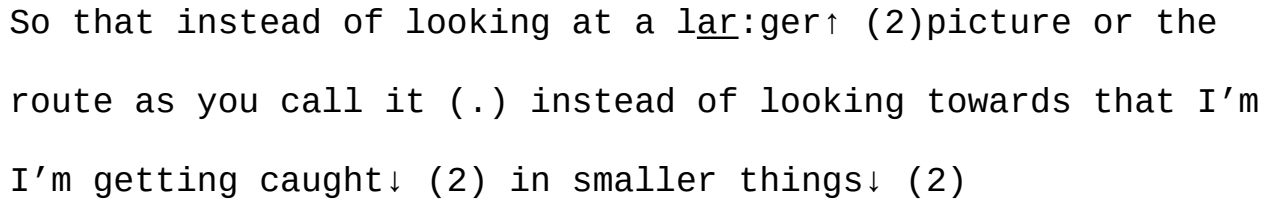

Therapist: $\mathrm{hm}(2)$

Lisa: but with a big des(h)ire=

Therapist: $\mathrm{hm} \mathrm{mm}$

Lisa: =to really more forward but $I^{\prime} m$ getting stuck=

Therapist: $\mathrm{hm} \mathrm{mm}$

Lisa: $\quad=y o u$ know $\downarrow$ in $<$ smaller $>$ (1) places $\downarrow$

Therapist: $\mathrm{hm}(2)$ 
Lisa: >so it applies very much< because I think that that's what $<I^{\prime} m$ try:ing to do: $\downarrow>$ and even in the last month since we had this last big (.) fl:y apart (.) um (.) I'm (.) I'm very much trying to look at a larger picture (1) and not make little things as impor $\uparrow$ tant

Therapist: $\mathrm{hm}$

Lisa: $\quad=<$ in the interest of (.) something $>$ (1) larger

Here, Lisa orients to the institutionalised nature of the therapy session, wherein 'doing being reflective' is expected, acceptable, and even encouraged. Notably, DP is against the notion that people just say what is in their head or that people simply say the same thing in different contexts. Rather, what counts as contextually relevant in a DP study is made visible in and through the participants’ orientations. More particularly, the primary social action accomplished here is that of 'being reflective.' Through turns of phrases such as, 'looking at a larger picture' and 'I'm very much trying to look at a larger picture', Lisa's performs 'vulnerability’ and 'honesty.' Further, we note here that Lisa also draws upon a metaphor that was previously evoked by the therapist, 'fly apart'. In so doing, she locates the rationale for 'being reflective' in relation to the presumably problematic event, which she positions herself as 'trying' to work on. Related to this, in Extract 2, Michael's language produces the social action of complaint, particularly a complaint about Lisa.

Extract 2

Michael: and tha:t (0.8) in her perspec $\uparrow$ tive (0.6) she's made some $(0.4)$

$$
\mathrm{e}::: r(0.8) \text { e::r }
$$

Therapist: ${ }^{\circ} \uparrow \mathrm{hm}^{\circ}$

Michael: ju:dgments or decisions or observation[ns a::n]d $u:: m,=$

Therapist: $\quad\left[{ }^{\circ 0} \mathrm{hm} \mathrm{mm}{ }^{\circ 0}\right]$ 


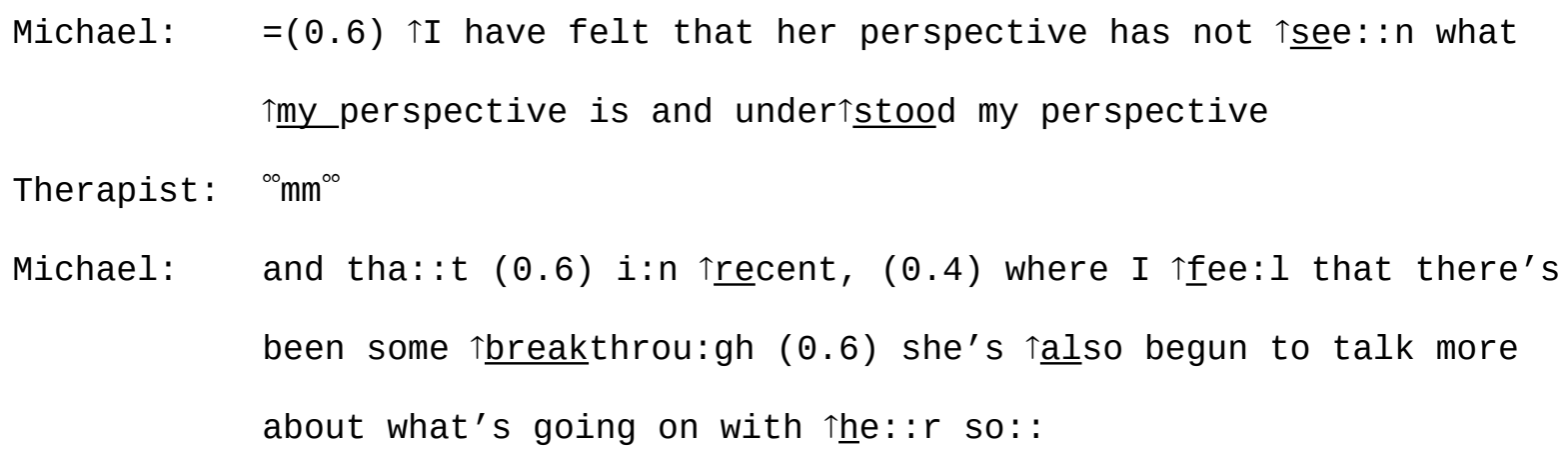

In Extract 2, Michael offers a complaint that Lisa has not understood his perspective, something he says multiple times, in differing ways, across the therapy session. In this

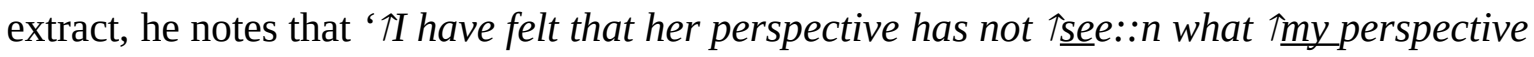
is'. Repetition in talk often serves to emphasise the point being made, and thus across the therapy session Michael emphasises his complaint of not being 'understood' by Lisa through repetitive language use. Sandwiched between this complaint, Michael states that "there's

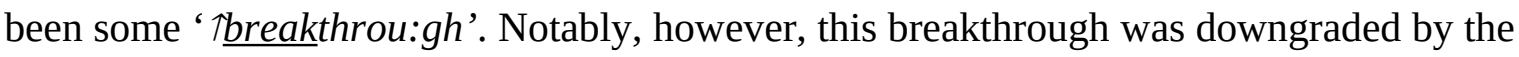
use of the word 'some' and 'only been recently', serving to minimise the extent or degree of this 'Threakthrou:gh'. Rhetorically, then, the initial complaint of not being understood stands as factual, given a 'recent' breakthrough may not be lasting.

\section{Fact and Interest}

The second distinctive feature of DP as demonstrated in the DAM, is its attention to the way that the facticity of claims is constructed in dialogue. Descriptions of people and events are often presented as simple 'facts' rather than positions, or invested claims. As such the delicate issue of managing any perceived vested interest in how those descriptions are received and how they form opinions of self, others and situations, are often carefully packaged. This is important, as such inferences on the part of the hearer may potentially draw into question the validity of the speaker's claims. Therefore, the way that the speaker's 
'interest' or stake in how these descriptions are received is integral to the plausibility of their accounts. Furthermore, any inference from the hearer that the speaker may have some intention behind presenting him/herself or another in a certain light can be managed.

In the section of data under analysis, we turn to an extract from Michael talking about his partner Lisa, as an illustrative example of how facts are built systematically in sections of talk. DP considers talk to be inherently rhetorical (Billig, 1987) and as such, descriptions are often designed to counter potential alternative versions (Edwards and Potter, 1992), and to simultaneously work to manage perceptions of interest or stake. Descriptions can potentially therefore be constructed with either offensive or defensive rhetoric (Potter, 1996a). In the following extract (Extract 3), there are two claims that Michael makes about Lisa: first, that unlike him, Lisa does not have a problem expressing her fear and anger, and second, that she is unpredictable. Clearly, in a setting such as therapy, all parties involved have some vested interest in how they themselves are perceived by the others present, and in the veracity of their own claims being accepted. What is at stake for Michael is the plausibility of the version of Lisa that he builds through his talk.

Extract 3

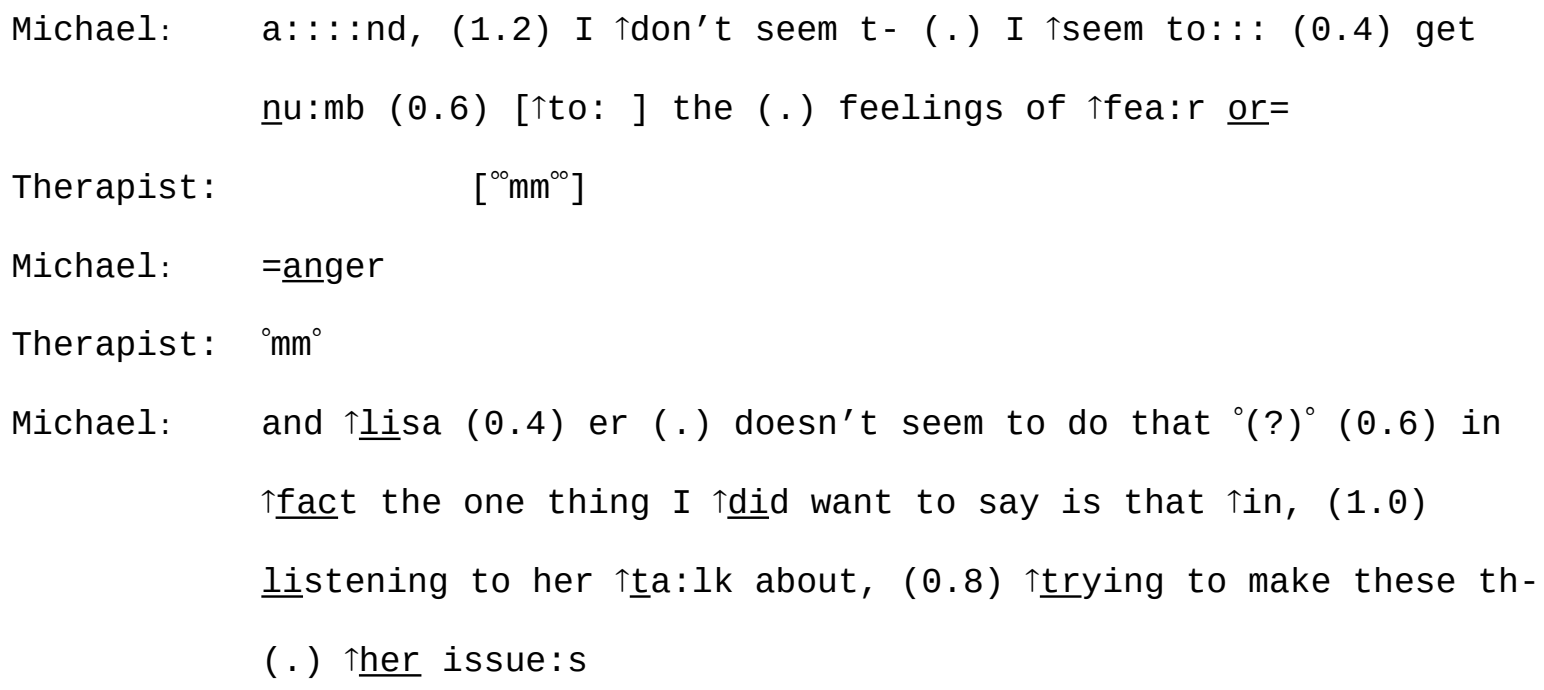


Michael: the only thing I wanted to say is I su个ppose where it gets Thard for me:: and difficult (0.4) i:s (1.6) I never kno::W (๑.8) w: : which issue she's dealing wi:th

Therapist: ${ }^{\circ} \mathrm{hm} \mathrm{mm},{ }^{\circ}(0.4){ }^{\circ} \mathrm{hm} \mathrm{mm},{ }^{\circ 0}$

Michael: that $\uparrow$ there is a sense of unpredictableness

In the first few sentences, one of the rhetorical devices used to organise the account as being heard as factual, is the use of contrast (Edwards, 2005). Michael presents himself emotionally in relation to fear and anger as 'numb' unlike Lisa who 'doesn't seem to do that'. Without making a direct statement about Lisa’s temperament therefore, Michael accomplishes establishing Lisa as the opposite of numb, and the hearer is left to fill in the blank about what this might be. This is an example that demonstrates what in DP terms is referred to as 'emotion talk', as psychological constructs are utilised to manage the interaction. The use of the words 'fear' and 'anger' in his self-description guide the hearer into making particular kinds of inferences about Lisa's experience (and expression) of these particular emotions. The use of the softener phrases 'I seem to' and 'Lisa er doesn't seem to' have the effect of presenting what Michael says as tentative, and not directly identifiable as the social action of accusation. This serves to manage perceived interest and better positions his statements to be heard as a factual. Additionally, his repetition of the phrase 'the one thing I did want to say' and again 'the only thing I want to say' functions to draw attention to and emphasize this issue that he is presenting in relation to Lisa.

In the latter part of the extract, Michael presents a further construction of Lisa's behaviour, which is formulated relative to what is 'difficult' for him. In this instance, Michael states 'I never know which issue she's dealing with'. Interestingly, although at face value this appears to be a description of his struggle, the a priori assumptions underlying this apparent self-disclosure are that Lisa has several 'issues' or problems, and that her struggles with these 
difficulties are apparent from her behaviour. By making the topic his confusion, this positions his description of Lisa as a previously uncontested fact on which his discussion of his own confusion is built. Furthermore, the use of the phrase 'I never know' indicates that this is a regular, on-going feature of their relationship. In the last sentence, his statement 'there is $a$ sense of unpredictableness' does not directly accuse Lisa of being unpredictable. However, this non-agentive description is one way to inoculate against a potential rebuttal of his claims as being 'interested', therefore establishing what he said about her as more of a neutral factual account. In relation to the wider discussion in this scenario, Michael's positioning of Lisa as someone with numerous, 'issues', as fearful, angry and unpredictable, also relates to building his own rebuttal of accountability for not being very 'open'.

\section{Accountability}

Being accountable refers to speakers' actions, which display that they are mitigating against any responsibility for an action in a social situation, with accounts potentially emerging in the form of an apology, defence, excuse, justification or explanation (Buttny, 1993). Accounting for one's behaviour can have a face-saving function, as being called to account often has implications for a person's image of good character and may be discrediting as an expression of a moral or social failing; thus, an account can prevent threats to face (Goffman, 1955). In this sense, accounts can serve a specific function, as what is often at stake for a speaker is a claim to good character (Buttny, 1993).

Accountability is a core feature of the DAM, and is a social action that analysts often explore, particularly as family therapy tends to be entrenched in accounts that serve to display how people are working, at the level of talk, to justify or defend their position and even engage in face-saving actions. In fact, Potter et al (1993) distinguish two levels of accountability, the first being the account that may be required for the original behaviour, and 
the second being the action of reporting that event in the current interaction. We present such an example from the data below:

Extract 4

Lisa: >And I see that (.) you know (.) I see people around me (.) I

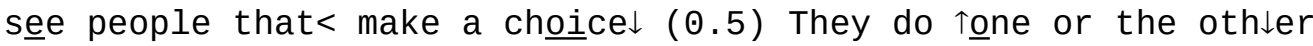
$(\odot .3)$. hh an neither of them in itself looks very appea:ling to me

Therapist: ${ }^{\circ} \mathrm{Hm}{ }^{\circ}$

Lisa: I mean there are people that are-(0.2) that do not allow themselves $(2.8)$

Therapist: ${ }^{\circ} \mathrm{Hm}{ }^{\circ}$

Lisa: to really become (3.2) tha:t close to another person $\downarrow$ (1.0)

Andersen: ${ }^{\circ} \mathrm{Hm} \mathrm{mm}^{\circ}$

Lisa: $\quad$ >and they're ve:ry independent $\downarrow<$

Andersen: ${ }^{\circ} \mathrm{Hm} \mathrm{mm}{ }^{\circ}$

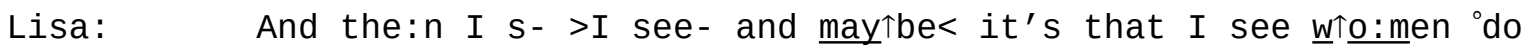
tha $\downarrow t^{\circ}$ it might be (๑.5) you know that I look at men an-) (2.0) an $\uparrow I$ see wome: $n$ (3.5) who become so merged that they completely lo:se any $y^{\prime}$ know(0.5) desi:res that they had (0.1) previously $\downarrow$ (๑.3) previous to the-

In her turn, Lisa presents an account that orients to the tension she feels as she balances being part of a couple, and being an independent woman. By constructing gender identity as a relevant feature of her account, Lisa aligns herself with the generic gender constructs of the dependent or independent woman. Utilising a contrast structure (cf, Smith, 1978) she demonstrates that some women keep a distance from partners and are 'very independent', while others 'become so merged they completely lose any desires', suggesting they are too immersed in their intimate relationships. In developing this narrative, Lisa is accounting for 
her own fears through the implication of her current situation, aligning with an image of a woman that does not suit her. Notably, the subject positioning of these two different types of women is dichotomous, positioning two extremes of a gender identity. This building of an account through the descriptions of female identities is done in a way that is generic and normative, orienting to the sociological ways of positioning women in general. Thus, by not offering an account of a specific woman, she offers a broad description of 'women', and in so doing makes any counter claim more complex to offer. Indeed, the systematic use of vagueness in interaction has been shown in previous DP research to guard against the possibility for the claim being disputed by other parties (Stancombe and White, 2005).

Extract 5 illustrates how an account is generated in response to the version of reality presented by Lisa. Here, we see how Michael engages in a great deal of interactional work to defend his character and account for his behaviour in response to Lisa's negative construction of him.

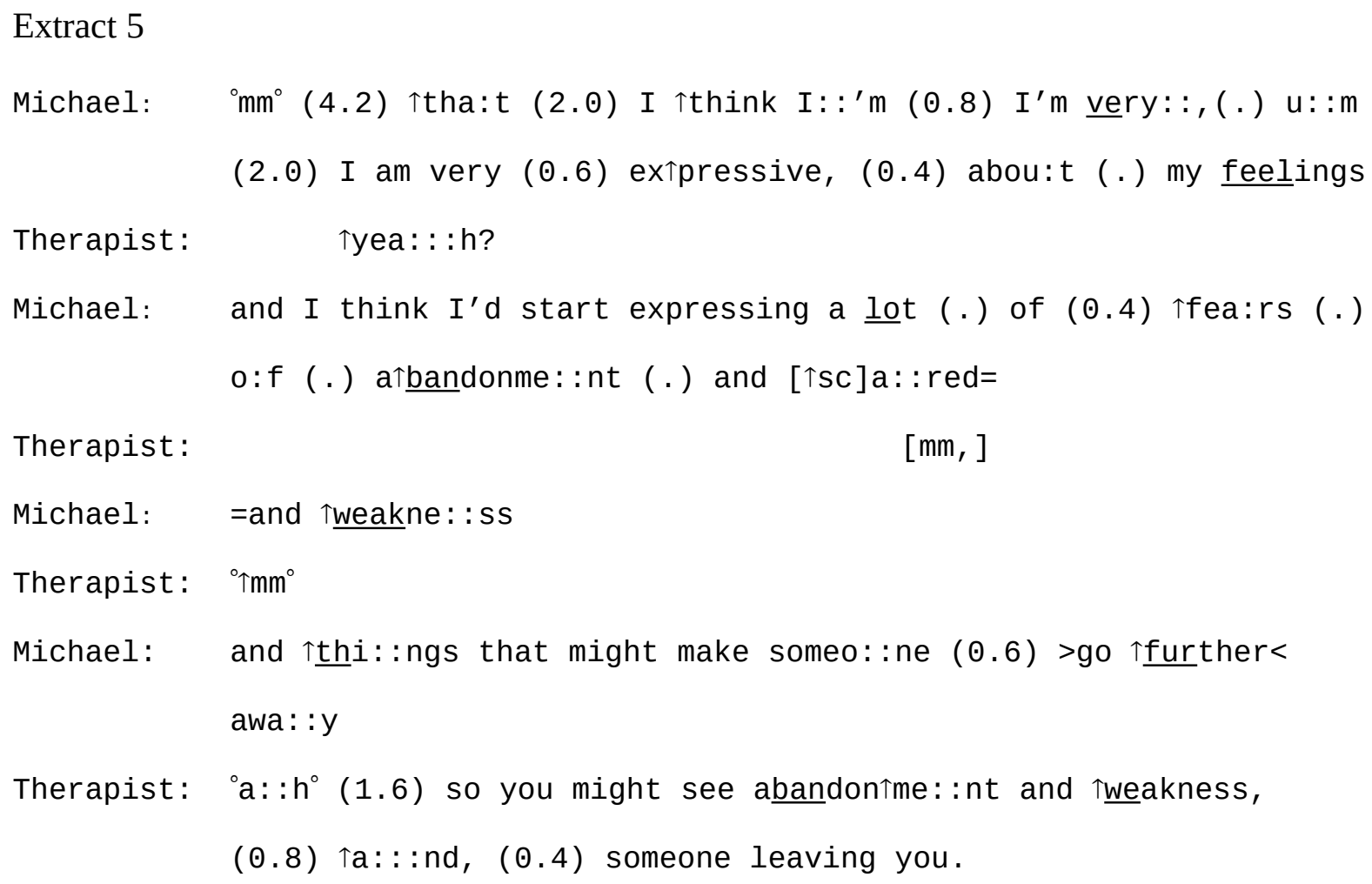




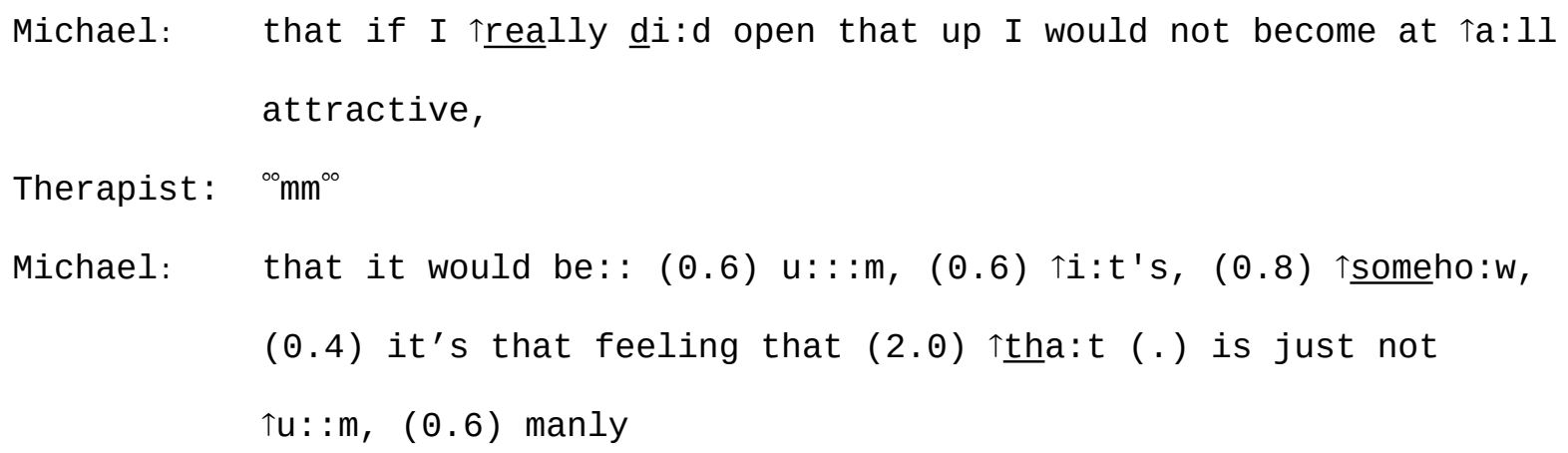

Notably, Michael's account is in response to Lisa's criticism of his dispositional character and thus is invoked in defence. Here, Michael provides an account of his personal expressions of emotion as being 'expressive', particularly in terms of his 'fears of abandonment', which is contrary to the way Lisa has constructed him. He notes however the tensions that such emotional expression creates in terms of how this may threaten his masculine identity and his view of Lisa's expectations of how a man should behave. In so doing, he accounts for his masculine behaviour and failing to open up in the way Lisa is currently complaining about, as being her fault, as his version is that she would not find that 'attractive'. This account, therefore, subtly places blame on Lisa for how Michael expresses himself, as he deflects taking personal responsibility for his behaviours. Two levels of accountability are observable in this interaction, in that Michael both accounts for his behaviour and also orients to the potential accountability of blaming Lisa during the family therapy session. In making this claim, he suggests that opening up is not beyond his capability, but something that is positioned as not masculine and contrary to Lisa's desire.

\section{DISCUSSION}

The use of the DAM to make sense of naturally occurring family therapy practice allows for an understanding of some of the complexities and subtleties of social interaction. Through our analysis, we demonstrated that the interlocutors use language in specific ways as they performed particular social actions and managed their stake in the presented version of 
events. Although we have presented the DAM as three separate elements for the sake of clarity and pedagogy and have only provided a brief overview of this specific discursive approach, we recognise the overlapping nature of the core concepts. These concepts were shown to be social action, fact and interest, and accountability and we have demonstrated how these serve as fundamental principles underpinning much DP work.

Through our analysis utilising the principles of the DAM, we have demonstrated that the couple in the family therapy utilised a range of discursive resources to manage their accountability, both within the therapy itself, and with reference to events outside. Using social actions such as performing vulnerability and honesty, Lisa worked to present a certain identity to the therapist. Juxtaposed with this was Michael's account and social action of a complaint, as he worked to counter some of the identity positioning presented by Lisa. We recognised that both parties in the interaction had at stake a positive identity as a good 'partner', and thus demonstrated plausibility of each version presented. Such accounting from Michael was presented emotionally as he discursively navigated his emotional position within the therapy as not being as open as he could be due to Lisa’s constructed unpredictability.

\section{Benefits of discursive psychology for couple and family therapists}

Although couple and family therapists are starting to see the value of undertaking research using DP, we would argue that there is scope for it to be more fully utilised by clinical professionals. One of the differences between individual therapy and couple or family therapy is the systemic element where other parties who may be constructed or complained about in certain ways are likely to be present in the therapeutic session rather than talked about in their absence. Therefore, a sophisticated analytic tool such as DP can be really helpful in teasing out the nuances of the accounting practices that family members may use. 
Within this environment, the alignment practices used by the therapist can also be investigated systematically. What DP offers therapists is an opportunity to reflect on the turnby-turn sequential organisation of the discursive practices used by both therapists and clients to ascertain both good practice examples of therapeutic interventions as well as teasing apart the complexities of couple and family relationships.

We make the case that DP is a natural fit for the field of therapy for a range of reasons. We have demonstrated that the preference for naturally occurring data is consistent with the clinical training that family therapists receive. Furthermore, family therapists have access to naturally occurring therapy data, and it is typical to record sessions for training and supervision purposes. This is particularly the case for family therapists who attune to social constructionist approaches to therapy, as the familiarity with DPs epistemological framework will facilitate an understanding of the approach. The focus on language and social action, as well as the social construction of reality, is something that family therapists manage in their everyday practice. DP therefore begins to provide new opportunities for practitioners and academics to form collaborative partnerships (O’Reilly and Kiyimba, 2015). This is because one of the strengths of DP when applied to therapy is its emphasis not just on what therapists do, but how they do it. In such a way, findings from DP research can be used as a training tool by identifying instances of best practice (Stokoe, 2014).

\section{Conclusions}

This paper has showcased how DP can be used to analyse sections of naturally occurring data from a family therapy session. The aim was to differentiate DP from other language-based methodologies. Specifically, we have focused on the central tenets of the DAM, describing each of the three core components and demonstrating how to apply them to data. We have argued for the value of reflective therapists using DP as an analytic approach. Additionally, 
DP has been positioned as a useful tool for researchers interested in studying the practices of couple and family therapy. In presenting the reader with the tools for conducting DP research, as well as a worked example, we hope to have provided a foundational understanding of the approach, and given a basic insight into its principles. 


\section{REFERENCES}

Andersen, T. (1992). Reflections of reflecting with families. In S. McNamee, \& K. Gergen, (Eds). Therapy as a social construction (pp: 54-68). London: Sage.

Andersen, T. (1987). The reflecting team: Dialogue and meta-dialogue in clinical work. Family Process, 26, 415-428.

Antaki, C., Billig, M., Edwards, D., and Potter, J. (2003). Discourse analysis means doing analysis: A critique of six analytic shortcomings’ Discourse Analysis online, online.

Avdi, E., \& Georgaca, E. (2007). Discourse analysis and psychotherapy: A critical review. European Journal of Psychotherapy and Counselling, 9(2), 157-176.

Billig, M. (1987). Arguing and thinking: A rhetorical approach to social psychology. Cambridge: Cambridge University Press

Burck, C. (2005). Comparing qualitative research methodologies for systemic research: the use of grounded theory, discourse analysis and narrative analysis. Journal of Family Therapy, 27, 237-262.

Burr, V. (2003). Social constructionism, second edition. London: Routledge

Buttny, R. (1993). Social accountability in communication. London: Sage.

Chenail, R., \& Morris, G. (1995). Introduction: The talk of the clinic. In G Morris \& R Chenail (Eds). Talk of the clinic: Explorations in the analysis of medical and therapeutic discourse. (pp:1-18).

Diorinou, M., \& Tseliou, E. (2014). Studying circular questioning ‘in situ’: Discourse analysis of a first systemic family therapy session. Journal of Marital and Family Therapy, 40(1), 106-121.

Edwards, D. (2000). Extreme case formulations: Softeners, investment, and doing nonliteral. Research on language and social interaction, 33(4), 347-373.

Edwards, D. (2005). Moaning, whinging and laughing: the subjective side of complaints. 
Discourse Studies, 7 (1), 5-29.

Edwards, D. (2012). Discursive and scientific psychology. British Journal of Social Psychology, 51, 425-435.

Edwards, D., \& Potter, J. (1992). Discursive psychology. London: Sage.

Goffman, E. (1955). On face-work: An analysis of ritual elements of social interaction. Psychiatry, 18, 213-231.

Horton-Salway, M. (2001). Narrative identities and the management of personal accountability in talk about ME: A discursive psychology approach to illness narrative. Journal of Health Psychology, 6(2), 247-259.

Jefferson, G. (2004). Glossary of transcript symbols with an introduction. In G. H. Lerner (Ed). Conversation analysis: Studies from the first generation (pp. 13-31). Amsterdam: John Benjamins.

Jørgensen, M. W., \& Phillips, L. J. (2002). Discourse analysis as theory and method. Sage.

Kiyimba, N., \& O’Reilly, M. (2016). The value of using discourse analysis to explore counselling and therapeutic interactions. In O’Reilly, M., \& Lester, J. (Eds). The Palgrave handbook of adult mental health: Discourse and conversation studies (pp: 520-539). Basingstoke: Palgrave Macmillan.

Lange, R. (2010). The family as its own reflecting team: a family therapy method. Journal of Family Therapy, 32, 398-408.

Lester, J. N. (2011). Exploring the borders of cognitive and discursive psychology: A methodological reconceptualization of cognition and discourse. Journal of Cognitive Education and Psychology. 10(3), 280-293.

Lester, J., \& O’Reilly, M. (2015). Is evidence-based practice a threat to the progress of the qualitative community? Arguments from the bottom of the pyramid. [Special issue; $20^{\text {th }}$ Anniversary edition] Qualitative Inquiry, 21(7), 628-63 
McLeod, J. (2001). Qualitative Research in Counseling and Psychotherapy. London, Sage.

McNamee, S., \& Gergen, K. (1992). Introduction. In S McNamee \& K Gergen (Eds.), Therapy as a social construction. (pp 1-6). London: Sage

Ness, O., \& Strong, T. (2014). Relational consciousness and the conversational practices of Johnella Bird. Journal of Family Therapy, 36, 81-102.

Ness, O., \& Strong, T. (2013). Learning new ideas and practices together: A cooperative inquiry. Journal of Family Psychotherapy, 24, 246-260.

O’Reilly, M., and Lester, J. (in press, a). Examining mental health through social constructionism: The language of mental health. Basingstoke: Palgrave MacMillan.

O’Reilly, M., \& Lester, J. (in press, b). Building a case for good parenting in a family therapy systemic environment: Resisting blame and accounting for children’s behaviour. Journal of family therapy

O’Reilly, M. \& Kiyimba, N. (2015). Advanced qualitative research: A guide to contemporary theoretical debates. London: Sage.

O’Reilly, M. \& Parker, N. (2014) “She needs a smack in the gob”: negotiating what is appropriate talk in front of children in family therapy. Journal of Family Therapy, 36 (3), 287- 307.

Patrika, P., \& Tseliou, E. (2016). Blame, responsibility and systemic neutrality: A discourse analysis methodology to the study of family therapy problem talk. Journal of Family Therapy, 38: 467-490

Pilnick, A., Hindmarsh, J. \& Gill, V. T. (2010). Beyond ‘doctor and patient’: Developments in the study of healthcare interactions. In A. Pilnick, J. Hindmarsh \& V. T. Gill (Eds.), Communication in healthcare settings: Policy, participation and new technologies (pp. 1-16). West Sussex: John Wiley and Sons.

Potter, J. (2012). Discourse analysis and discursive psychology. In Cooper, H. (Editor-in- 
Chief). APA handbook of research methods in psychology: Vol. 2. Quantitative, qualitative, neuropsychological, and biological (pp. 111-130). Washington: American Psychological Association Press.

Potter, J. (2002). Two kinds of natural. Discourse Studies, 4(4), 539-542.

Potter, J. (1996). Representing reality: Discourse, rhetoric, and social construction. London: Sage.

Potter, J., Edwards, D., and Wetherell, M. (1993). A model of discourse in action. American Behavioral Scientist, 36 (3), pp. 383 - 401.

Potter, J. \& Hepburn, A. (2005). Qualitative interviews in psychology: problems and possibilities. Qualitative Research in Psychology, 2, 1-27.

Potter, J., \& Hepburn, A. (2008). Discursive constructionism. In J. A. Holstein \& J. F. Gubrium (Eds.), Handbook of constructionist research (pp. 275-293). New York: Guildford.

Potter, J., \& Wetherell, M. (1987). Discourse and social psychology. London: Sage.

Priebe, S., \& McCabe, R. (2008). Therapeutic relationships in psychiatry: The basis of therapy or therapy in itself? International Review of Psychiatry, 20 (6), 521-526.

Reynolds, J. (2013). The single woman: A discursive investigation. New York, NY: Routledge.

Rhodes, P. (2011). Why clinical psychology needs process research: An examination of four methodologies. Clinical Child Psychology, 17 (4), 495-504.

Roy-Chowdhury, S. (2006). How is the therapeutic relationship talked into being? Journal of Family Therapy, 28, 153-174

Roy-Chowdhury, S. (2003). Knowing the unknowable: what constitutes evidence in family therapy? Journal of Family Therapy, 25, 64-85.

Sacks, H. (1987). 'You want to find out if anybody really does care'. In G. Button \& J. R. 
Lee (Eds), Talk and social organization (pp. 219-225). Clevedon: Multilingual Matters Ltd.

Schön, D. A. (1987). Educating the reflective practitioner: Toward a new design for teaching and learning in the professions. San Fransisco, CA: Jossey-Bass.

Smith, D. (1978). 'K is mentally ill': The anatomy of a factual account. Sociology, 12, 23-53.

Speer, S. (2002). 'Natural' and 'contrived' data: a sustainable distinction? Discourse Studies. 4 (4): 511-525.

Stancombe, J., \& White, S. (2005). Cause and responsibility: Towards an interactional understanding of blaming and 'neutrality' in family therapy. Journal of Family Therapy, 27, 330-351.

Stokoe, E. (2014). The conversation analytic role-play method (CARM): A method for training communication skills as an alternative to simulated role-play. Research on Language and Social Interaction, 47(3), 255-265.

Strong, T., Busch, R., \& Couture, S. (2008). Conversational evidence in therapeutic dialogue. Journal of Marital and Family Therapy, 34 (3), 388-405.

ten Have, P. (2002). Ontology or methodology? Comments on Speer's 'natural' and ‘contrived’ data: a sustainable distinction? Discourse Studies, 4(4), 527-530.

Tseliou, E. (2013). A critical methodological review of discourse and conversation analysis studies of family therapy. Family Process, 52 (4), 653-672

Wetherell, M. (2001). Debates in discourse research. In M. Wetherell, S. Taylor, \& S. J., Yates (Eds.), Discourse theory and practice: A reader (pp. 380-399). London: Sage.

Wood, L. A., \& Kroger, R. O. (2000). Doing discourse analysis: Methods for studying action in talk and text. Thousand Oaks, CA: Sage. 


\section{Appendix A}

Jeffersonian Transcription Conventions (Jefferson, 2004)

\begin{tabular}{|c|c|}
\hline $\begin{array}{l}\text { Transcription } \\
\text { Symbol }\end{array}$ & Explanation \\
\hline (.) & $\begin{array}{l}\text { A period within parenthesis represents a micro pause, which is hearable } \\
\text { but not long enough to measure. }\end{array}$ \\
\hline$(0.2)$ & A number inside a parenthesis denotes a hearable and measurable pause. \\
\hline$[\quad]$ & Square brackets are used to denote overlapping speech. \\
\hline$><$ & $\begin{array}{l}\text { A greater than-less than symbol represents a quickened pace of the } \\
\text { speech. }\end{array}$ \\
\hline$<>$ & $\begin{array}{l}\text { A less than-greater than symbols represented a slowed pace of the } \\
\text { speech slowed. }\end{array}$ \\
\hline$(\quad)$ & $\begin{array}{l}\text { A blank space within a parenthesis represents that spoken words were } \\
\text { unclear and not able to be transcribed. }\end{array}$ \\
\hline$\left(\left(\begin{array}{ll}( & )\end{array}\right)\right.$ & $\begin{array}{l}\text { A description of contextual information within double parenthesis is } \\
\text { used when no other symbol is available. }\end{array}$ \\
\hline$\uparrow$ & $\begin{array}{l}\text { An underlined word or part of a word represents a rise in volume or } \\
\text { emphasis. }\end{array}$ \\
\hline$\downarrow$ & An upward arrow represents a rising intonation. \\
\hline CAPITALS & A downward arrow represents falling intonation. \\
\hline Hum(h)our & Capital letters represents that something was said loudly or shouted. \\
\hline$=$ & A bracketed ' $h$ ' represents laughter in the talk. \\
\hline$\because::$ & An equal sign represents latched speech. \\
\hline hhh or .hh & $\begin{array}{l}\text { Colons represents elongated or stretched sound. } \\
\text { 'hhh' or '.hh' represents outbreath or inbreaths }\end{array}$ \\
\hline
\end{tabular}

